\title{
Psychiatric morbidity and substance use correlated with drug compliance among subjects with essential hypertension attending the out-patient clinic of university of Port Harcourt teaching hospital (UPTH)
}

\begin{abstract}
Background: Essential hypertension, a non-communicable disease, commonly of adult and the aged, is fast assuming an epidemic dimension. Psychiatric comorbidity and substance use tend to affect drug compliance as well as outcome of the disease.
\end{abstract}

\begin{abstract}
Aim: The aim of this study, therefore, was to determine common psychiatric comorbidity, substance use and medication adherence among patients with essential hypertension at the University of Port Harcourt Teaching Hospital.
\end{abstract}

Methods: A cross-sectional study was conducted among 360 hypertensive patients on follow-up at Cardiovascular Clinic of the General Outpatient Department of the University of Port Harcourt Teaching Hospital. Structured questionnaires were used to assess alcohol use, Kolanut chewing, caffeine use, cigarette smoking, tramadol, codeine, cannabis, and cocaine. Psychiatric comorbidity was assessed using the GHQ-12 in conjunction with the DSM 5. Data was analysed using the SPSS version 20.

Results: The prevalence of psychological morbidity among hypertensive patients was $31.6 \%$. Of the total participants, $62(17 \%)$ of them had alcohol use disorders,cigarette smoking $44(12.2 \%)$, Nicotine snuffing $6(1.7 \%)$, kolanut and khatchewing $15(4.2 \%)$, tramadol $17(4.7 \%)$, codeine $14(3.9 \%)$, caffeine $12(3.3 \%)$, cannabis $8(2.2 \%)$ and cocaine $5(1.4 \%)$.Of the $104(28.9 \%)$ who had ever missed or discontinued medications, $37(35.6 \%)$ had psychiatric comorbidity, 23(22.1\%) has substance use, 25(24.0\%) had both psychiatric and substance use comorbidity while $19(18.3 \%)$ had no psychiatric or substance use comorbidity $(\mathrm{p}=0.001)$

Conclusion: Psychological morbidity and substance use are prevalent among hypertensive patients on follow-upat the hospital. The findings of the study imply that there is a need for further studies to understand the effect ofpsychological morbidity on the clinical outcomes of hypertensive patients.

Keywords: psychological morbidity, substance use, essential hypertension, port harcourt
Volume 5 Issue 3 - 2018

\section{Nkporbu AK, Stanley PC \\ Department of Neuropsychiatry, University of Port Harcourt Teaching Hospital, Nigeria}

Correspondence: Nkporbu AK, Consultant Neuropsychiatrist, Department of Neuropsychiatry, University of Port Harcourt Teaching Hospital, Nigeria, Tel 08036772778 , Email nakpigi2008@yahoo.com

Received: May 29, 2018 | Published: June 19, 2018
Abbreviations: DALYs, disability adjusted life years; NCDs, non-communicable diseases; WHO, world health organization; AUD, alcohol use disorders; GABA; gamma-aminobutyric acid; CNS, central nervous system; HIV, Human Immunodeficiency Virus; AIDS, acquired immune deficiency syndrome

\section{Introduction}

Worldwide, data from variety of studies have put the burden of mental health problems and substance use disorders to be greater than those of HIV/AIDS, asthma, tuberculosis, diabetes and traffic accident. ${ }^{1-3}$ Mental, substance use and neurological disorders constitute a high proportion of the world's disease burden in both high, low to middleincome countries. ${ }^{3}$ Hypertension is a major cardiovascular disease and common all over the world..$^{4-6}$ The productive age group seems to be the worst hit particularly for cardiovascular diseases productive age. ${ }^{4,5}$ Hypertension was a forefront risk factor for disability adjusted life years (DALYs) in 2010.7 Both cardiovascular disease as well as psychiatric conditions combined to contribute greater proportion to the world's total burden of non-communicable diseases (NCDs).$^{8-14}$ The World Health Organization (WHO) has estimated that not less than $25 \%$ of all patients who seek the services of health facilities both in rural as well as urban areas suffer from at least one mental, neurological or behavioural disorder, adding that most of which are undiagnosed or untreated. ${ }^{8,15}$ Patients with chronic medical illness like hypertension usually have the vulnerability for psychological problems due to difficulty in adjusting their aspirations, lifestyles, employment, and spending on treatment and medication and also have poor coping skills in the face of stressors. ${ }^{8-14}$ Many chronic illnesses, with or without psychological illnesses as consequence, may also be associated with substance use as double or triple diagnosis. ${ }^{16-23}$

Various definitions have been given to hypertension and have undergone modifications over the years. The generally accepted definition is that Hypertension is a sustained elevation in blood pressure over an acceptable upper limit of normal values of systolic 
and diastolic blood pressures. ${ }^{24,25}$ Objectively and quantitatively, hypertension is blood pressure persistently equal to or greater than 140/90mmHg. ${ }^{24,25}$ Hypertension may be of unknown cause where it is called essential hypertension or hyperpiesia, or may have an underlying biological or environmental cause when it is known as secondary hypertension. ${ }^{24,25}$ The World Health Organization/ International Society of Hypertension classified hypertension into mild, moderate, severe and high normal. ${ }^{26}$ (Table 1).

Table I Modern Classification of Hypertension by the World Health Organization /International Society of Hypertension

\begin{tabular}{lll}
\hline Category (B.P.) & Systolic blood pressure $\mathbf{( m m H g )}$ & Diastolic BB $(\mathbf{m m H g})$ \\
\hline Optimal & $<120$ & $<80$ \\
\hline Normal & $<130$ & $<85$ \\
\hline High normal & $<130-139$ & $<85-89$ \\
\hline Hypertension & High normal & $90-99$ \\
\hline Grade I (mild) & $140-159$ & $100-109$ \\
\hline Grade 2 (moderate) & $160-179$ & 110 \\
\hline Grade 3 (severe) & 180 & $<90$ \\
\hline Isolated systolic hypertension & 180 & \\
\hline
\end{tabular}

As a leading non-communicable chronic disease, hypertension often requires long term treatment. ${ }^{26}$ Increasing urbanization and changing life styles around the world have equally continued to cause the rising incidence. ${ }^{27-30}$ Hypertension is regarded as major public health problem, ${ }^{31}$ and has continue to constitute a major threat to the health of adults in particular in sub-Saharan Africa. ${ }^{32,33}$ Different researches have put the prevalence to range from $25 \%$ to $35 \%$ among adults aged 25 to 64 years with an estimated 20 million people being affected in the African Region. ${ }^{32,34-40}$ Globally, the prevalence of hypertension is $25 \%,{ }^{40}$ with an estimated 972 million $(26.4 \%)$ adults being affect, out of which 333 million (34.26\%) are in the developed and 639 million (65.73\%) in developing countries. ${ }^{38}$ It has been projected that by the year 2025 , about 1.56 billion of the world population will have hypertension. ${ }^{39}$ Hypertension is estimated to cause 7.1 million deaths, which is about $13 \%$ of all cases. ${ }^{39,40}$ A study done in Canada and six European countries, the age- and sex-adjusted prevalence of hypertension was 28 and $44 \%$ respectively. ${ }^{40}$

Nigeria as a developing country is equally witnessing a rising prevalence of hypertension probably due to adoption of western lifestyles and the stress of urbanization, both of which are capable of increasing the morbidity associated with unhealthy lifestyles. ${ }^{41}$ Racial composition of the population of the study and the criteria for defining the condition are equally strong determinants. ${ }^{42,43}$ Many studies done in Nigeria have stated that hypertension remains the commonest non communicable disease with over 4.3 million Nigerians above the age of 15 years being classified as hypertensive. ${ }^{32,33,39}$ Studies have estimated the overall prevalence rate of hypertension in Nigeria to be within the range of 1.2-1.8\%[34-37].Environmental and behavioural factors like salt intake, occupation ${ }^{44}$ and alcohol intake, cigarette smoking and use of other psychoactive substances, ${ }^{17-23,27,28}$ family size, ${ }^{39}$ prolonged period of unemployment and poverty, ${ }^{45}$ overcrowding and other life stressors, impaired intrauterine growth ${ }^{46}$ and lack of exercise have been implicated in the development of hypertension.

Studies have observed direct link between use of alcohol (daily $>14 \mathrm{~g}$ intake of ethanol) ${ }^{47-51}$ tobacco,${ }^{52-56}$ kolanut and khat consumption in men and women ${ }^{57-61}$ and isolated systolic high blood pressure. A study has observed that over $10 \%$ of the population using kola nuts regularly and or alcohol are hypertensive. ${ }^{39}$ Caffeine, cannabis and cocaine have equally been associated with hypertension..$^{27,28}$ From these findings, it became an obvious suggestion development of programs to improve management of hypertension should not only focus on lifestyle variables and their modifications like smoking and alcohol, but most importantly include the assessment and treatment of substance abuse and dependence disorders as well as other psychological morbidity. ${ }^{27,28,39}$

Studies have noted the relationship between depression and anxiety symptoms and medical treatment of hypertension. ${ }^{62,63}$ In the recent large scale review, DiMatteo et al. ${ }^{63}$ observed a strong association of depression with noncompliance with medical treatment. The odds for being noncompliant with medication recommendations were three times higher for depressed patients when compared to nondepressed patients. ${ }^{63}$ However, no association between anxiety and noncompliance was found, ${ }^{63}$ despite its predictive value in the development of hypertension.

Management of hypertension requires strick medication adherence for successful control and to better the quality of life and well being of the individual. Majority of drug treatment regimen for hypertensive patients is polytherapy and this may require additional dedication. Both psychiatric comorbidity as well as substance abuse can singly or in synergy affect drug adherence to anti-hypertensive medications. There had being consistent findings from various studies that have looked at the association between hypertension treatment and smoking and alcohol intake. Briganti et al., ${ }^{15}$ noted that male sex, younger age, extreme poverty, not being obese, insufficient physical activity, current smoking, and excessive alcohol intake were significantly associated with untreated hypertension compared with treated hypertension. The results also observed comorbidity with psychological disorders and substance abuse and dependence were associated with lack of hypertension treatment, too. The aim of this study, therefore, was to determine common psychiatric comorbidity, substance use and medication adherence among patients with essential hypertension. 


\section{Methodology}

Informed consent was obtained from the participants. A crosssectional study was conducted among 360 patients with hypertension who were on follow-up at the Cardiovascular Clinic of the General Outpatient Department of the University of Port Harcourt Teaching Hospital. Hypertensive patients who had primary myocardial or vascular disease, in cardiac failure, renal failure or who had a stroke, or coronary heart disease, diabetes mellitus, asthmatic illness, or any other chronic illnesses or those found to be acutely ill were excluded. Subjects selected were those who have been diagnosed for at least the past one year and have had at least six months of treatments, and were selected through simple random sampling. A structured sociodemographic questionnaire was used to obtained socio-demographic data of participants

\section{Screening for psychiatric comorbidity}

To assess psychiatric comorbidity, the GHQ-12, in conjunction with the DSM 5, was used.

\section{Screening for substance use}

Alcohol use disorders (AUD) was screened using the four item CAGE questionnaire, ${ }^{64}$ (cut down, annoyed, guilty, eye opener). ${ }^{64}$ Any participant who scored two or more on the CAGE was classified as having AUDs. ${ }^{64}$ Structured questionnaires were used to assess all the other psychoactive substances: Kolanut and khat chewing, caffeine use, cigarette smoking, tramadol, codeine, cannabis, and cocaine. In this study, current use was defined as use during the month preceding the interview.

\section{Data analysis}

The SPSS version 20 statistical package was used to analyzed the data. A correlation analysis was also done. Confidence interval was set at $95 \%$ while P-value of less than 0.05 was considered statistically significant.

\section{Results}

From the study, the mean age of hypertension was $44.59 \pm 7.86$. Those who had their onset of illness at the age of 40 years and above constituted 231(64.2\%) (Table 2) (Table 3) (Table 4).

Table 2 Socio-demographic and Clinical Characteristics of Subjects with Essential Hypertension and People Living with HIV (PLWHIV)

\begin{tabular}{lll}
\hline Variables & Hypertension=360 & Statistical analysis \\
\hline Age & Freq & \\
$<20$ yrs & $0(0.0 \%)$ & $\mathrm{X}^{2}=150.83$ \\
$20-29$ & $16(44 \%)$ & $\mathrm{df}=4 \mathrm{p}=0.00 \mathrm{I}$ \\
$30-39$ & $77(21.4 \%)$ & \\
$40-49$ & $132(36.7 \%)$ & \\
$\geq 50$ & $135(37.5 \%)$ & \\
Gender & & $\mathrm{X}^{2}=0.73$ \\
Male & $141(39.2 \%)$ & $\mathrm{df}=1 \mathrm{p}=0.39$ \\
Female & $219(60.8 \%)$ & \\
Marital status & & $\mathrm{X}^{2}=41.72$ \\
Married & $257(71.4 \%)$ & $\mathrm{df}=4 \mathrm{p}=0.00 \mathrm{I}$ \\
Single & $38(10.6 \%)$ & \\
Divorced & $3(0.8 \%)$ & $\mathrm{P}=0.006$ \\
Separated & $8(2.2 \%)$ & $\mathrm{X}=0.00 \mathrm{X}$ \\
Widowed & $54(15.0 \%)$ & \\
Educational & & \\
None & $17(4.7 \%)$ & \\
Primary & $76(21.5 \%)$ & \\
Secondary & $122(34.5 \%)$ & \\
Tertiary & $139(39.3 \%)$ & \\
Tribe & $5(1.4 \%)$ & \\
Hausa & $130(44.8 \%)$ & \\
Ibo & $28(7.8 \%)$ & \\
Yoruba & & \\
\hline & & \\
\hline
\end{tabular}

Citation: Nkporbu AK, Stanley PC. Psychiatric morbidity and substance use correlated with drug compliance among subjects with essential hypertension attending the out-patient clinic of university of Port Harcourt teaching hospital (UPTH). MOJ Addict Med Ther. 20I8;5(3): I48-I56. 
Table Continued

\begin{tabular}{|c|c|c|}
\hline Variables & Hypertension $=360$ & Statistical analysis \\
\hline Age & Freq & \\
\hline ljaw & $79(21.9 \%)$ & \\
\hline Ogoni & $44(12.2 \%)$ & \\
\hline lkwerre & $49(13.6 \%)$ & \\
\hline Others & $31(8.6 \%)$ & \\
\hline \multicolumn{3}{|l|}{ Occupation } \\
\hline Managers & $5(1.4 \%)$ & $X^{2}=64.47$ \\
\hline Professionals & $15(4.2 \%)$ & $\mathrm{df}=10$ \\
\hline Technicians and Associates professionals & $30(8.3 \%)$ & $p=0.001$ \\
\hline Clerical support workers & $46(12.8 \%)$ & \\
\hline Services and sales workers & $29(8.1 \%)$ & \\
\hline Skilled agricultural forestry and fishery workers & $30(8.3 \%)$ & \\
\hline Craft and related trade workers & $54(15.1 \%)$ & \\
\hline Plant and machine operators and assemblers & $47(13.1 \%)$ & \\
\hline Elementary occupation & $81(35.2 \%)$ & \\
\hline Armed forces occupation & $3(0.05)$ & \\
\hline Unemployed & $37(16.1 \%)$ & \\
\hline \multicolumn{3}{|l|}{ Ave. income } \\
\hline$\leq 10,000$ & $83(24.6 \%)$ & $X^{2}=20.86$ \\
\hline $10,000-30,000$ & $8 I(24.0 \%)$ & $\mathrm{df}=4$ \\
\hline $30,000-50,000$ & $77(22.8 \%)$ & $\mathrm{p}=0.00 \mathrm{I}$ \\
\hline $50,000-100,000$ & $54(16.0 \%)$ & \\
\hline$>100,000$ & $43(7 \%)$ & \\
\hline No income & 12() & \\
\hline Unable to estimate & $22(6.8 \%)^{*}$ & \\
\hline \multicolumn{3}{|l|}{ Rxn to diagnosis } \\
\hline Normal & $38(10.6 \%)$ & $X^{2}=109.83$ \\
\hline Sad & $175(48.6 \%)$ & $\mathrm{df}=\mathrm{I}$ \\
\hline Very Sad & $146(40.6 \%)$ & $\mathrm{P}=0.00 \mathrm{I}$ \\
\hline With to die & $\mathrm{I}(3 \%)$ & \\
\hline \multicolumn{3}{|l|}{ Mode of getting drugs } \\
\hline From government & $26(7.2 \%)$ & $X^{2}=483.53$ \\
\hline Self Purchase & $328(91.1 \%)$ & $\mathrm{df}=2$ \\
\hline Both & $6(1.7 \%)$ & $p=0.001$ \\
\hline \multicolumn{3}{|l|}{ Source of support } \\
\hline Charity Organization & $8(2.2 \%)$ & $X^{2}=9.87$ \\
\hline Friends & $3(8 \%)$ & $d f=3$ \\
\hline Relatives & $77(21.4 \%)$ & $\mathrm{p}=0.02$ \\
\hline None & $272(75.6 \%)$ & \\
\hline Stigma & & $X^{2}=153.62$ \\
\hline Yes & $4(1.1 \%)$ & $\mathrm{df}=\mathrm{I}$ \\
\hline
\end{tabular}

Citation: Nkporbu AK, Stanley PC. Psychiatric morbidity and substance use correlated with drug compliance among subjects with essential hypertension attending the out-patient clinic of university of Port Harcourt teaching hospital (UPTH). MOJ Addict Med Ther. 20I8;5(3): I48-I56. DOI: I0.15406/mojamt.2018.05.001 II 


\begin{tabular}{|c|c|c|}
\hline Variables & Hypertension $=360$ & Statistical analysis \\
\hline Age & Freq & \\
\hline No & $356(98.9 \%)$ & $\mathrm{p}=0.00 \mathrm{I}$ \\
\hline \multicolumn{3}{|l|}{ Domestic situation (Live With) } \\
\hline Partner & $37(10.3 \%)$ & $X^{2}=73.63$ \\
\hline Family & $307(85.3 \%)$ & $\mathrm{df}=3$ \\
\hline Friends & $7(1.9 \%)$ & $\mathrm{P}=0.00 \mathrm{I}$ \\
\hline None & $9(2.5 \%)$ & \\
\hline Partner & $37(10.3 \%)$ & \\
\hline Family & $307(85.3 \%)$ & \\
\hline Friends & $7(1.9 \%)$ & \\
\hline None & $9(2.5 \%)$ & \\
\hline \multicolumn{3}{|l|}{ Blood pressure (B.P) } \\
\hline \multicolumn{3}{|l|}{ B.P within normal range } \\
\hline Mild Hypertension & $119(20.2 \%)$ & \\
\hline Moderate hypertension & $161(27.3 \%)$ & \\
\hline Severe hypertension & $80(13.6 \%)$ & \\
\hline \multicolumn{3}{|l|}{ Age of onset of illness } \\
\hline$<20$ years & $0(0.0 \%)$ & $X^{2}=185.75$ \\
\hline $20-29$ years & $27(7.5 \%)$ & $d f=23$ \\
\hline $30-39$ years & $102(28.3 \%)$ & $\mathrm{P}=0.00 \mathrm{I}$ \\
\hline $40-49$ years & $169(46.9 \%)$ & \\
\hline$>50$ years & $62(17.2 \%)$ & \\
\hline \multicolumn{3}{|l|}{ Duration of illness } \\
\hline 5 years and below & $316(87.8 \%)$ & $X^{2}=10.29$ \\
\hline $6-10$ years & $30(8.3 \%)$ & $d f=2$ \\
\hline II years and above & $14(3.9 \%)$ & $\mathrm{P}=0.005$ \\
\hline \multicolumn{3}{|l|}{ Duration of treatment } \\
\hline$<$ I year & $74(20.6 \%)$ & $X^{2}=8.59$ \\
\hline $1-5$ years & $242(67.2 \%)$ & $\mathrm{df}=2$ \\
\hline $6-10$ years & $31(13.5 \%)$ & $\mathrm{P}=0.03$ \\
\hline$>10$ years & $2(0.9 \%)$ & \\
\hline Ever missed or discontinued treatment & & $X^{2}=7.79$ \\
\hline Yes & $104(28.9 \%)$ & $d f=1$ \\
\hline No & $256(71.1 \%)$ & $\mathrm{P}=0.04$ \\
\hline
\end{tabular}

Source: Researcher's field study.

Table 3 Summary of Psychiatry Diagnosis

\begin{tabular}{llll}
\hline SN & Psychiatric Morbidity Total & Total & Essential Hypertension (\%) \\
\hline I & Depressive disorders & 102 & 28.3 \\
2 & Anxiety disorders & 76 & 21.1 \\
4 & Mixed Anxiety and Depressive disorders & 21 & 5.8 \\
5 & Substance Abuse & 82 & 22.7 \\
12 & Nil (no psychiatric illness) & 79 & 21.9 \\
& Total & 360 & $100 \%$ \\
\hline
\end{tabular}

Citation: Nkporbu AK, Stanley PC. Psychiatric morbidity and substance use correlated with drug compliance among subjects with essential hypertension attending the out-patient clinic of university of Port Harcourt teaching hospital (UPTH). MOJ Addict Med Ther. 2018;5(3):I48-I56. DOI: 10.15406/mojamt.2018.05.00III 
Table 4 Distribution of Substance use among hypertensive patients

\begin{tabular}{lll}
\hline Psychoactive Substance & Frequency & $\%$ \\
\hline Alcohol & 62 & 17.2 \\
\hline Cigarette smoking & 44 & 12.2 \\
\hline Nicotine snuffing & 6 & 1.7 \\
\hline Kolanut and khat chewing & 15 & 4.2 \\
\hline Tramadol & 17 & 4.7 \\
\hline Codeine & 14 & $3.90 \%$ \\
\hline Caffeine & 12 & $3.30 \%$ \\
\hline Cannabis & 8 & $2.20 \%$ \\
\hline Cocaine & 5 & $1.40 \%$
\end{tabular}

Source: Result fromresearcher's field study. Data include cases of polysubstance use.

\section{Discussion}

From the study, strong direct association was observed between age and occurrence of hypertension as the prevalence was noted to be increasing with age. It was twice higher, in the age groups 40-49 and 50 and above, in comparism with age group of 30-39, and about 6 times higher compared with age group 20-29. This finding is in line with previous studies which noted that about 4.3 million Nigerians above the age of 15 years are classified as being hypertensive. ${ }^{38,39}$ In females especially, a substantial increase in the prevalence of hypertension occurs after the age of $50 .^{38,39}$ This is presumably attributed to the hormonal changes associated with menopause. ${ }^{24,38}$ The illness may progressively become worse with age causing attendant incapacitating symptoms that may infringe on the functional capacity of the individual and thereby reducing the quality of life. ${ }^{10,14,25}$

Age range of 40-49 formed the most prevalent age of onset of hypertension with $46.9 \%(\mathrm{n}=169)$. This finding tallied with other studies which had noted that the illness is commonest after 40 years. ${ }^{38}$ Equally worthy of note is that the number of patients steadily increased with increasing age of onset of illness with a sharp decrease from the age of 50. Hypertension which starts after the age of 50 years is most likely to be secondary hypertension. ${ }^{24}$ In females, the prevalence is related to age with a substantial increase occurring after the age of $50 . .^{38}$

Psychological morbidity are common among the hypertensive population, and the study found a prevalent of $55.3 \%{ }^{10,14}$ Depressive illness was higher and this is consistent with earlier studies. ${ }^{14}$ The psychopathogenesis of depression in hypertension could be easily explained. Hypertension is essentially a chronic illness with disabling and sometimes incapacitating symptoms. The persistent or frequency of occurrence of these symptoms, the dysfunctions, need to for long term medications, associated economic burden, emergent complications, overall affection of quality of life often may summed up to cause depression..$^{25}$ This reduces the zeal and often discourages the individual from further taking or adhering to medications. ${ }^{63}$ There is a perceived expectation in ailing individual that medications will substantially ameriorate the symptoms and bring about enormous relief.
However, in most chronic illnesses including hypertension in which one is required to take medications sometimes lifetime, this self encouragement may reduce or be lost. You may then observe irregularity in medication intake.

Psychological morbidity particularly depression affects negatively the management of hypertension, with most studies among men giving interesting revelations. ${ }^{62,63}$ Depression is known to impare adherence to medications and self-care regimens in patients with chronic diseases. ${ }^{63}$ The hopelessness and general lack of interest, ${ }^{25}$ both are key symptoms of depression and they make compliance difficult or impossible as the patient holds little optimism that any action will be worthwhile. Furthermore, the general loss or decrease in energy could equally play a role in causing medication non adherence..$^{63}$ Finally, both depression and anxiety associated with poor attention and concentration as well as variable degree of memory problems. ${ }^{25}$ This may cause some individuals with hypertension to ordinarily miss their medications. Definitive aetiological conclusions would therefore need a causal correlation from longitudinal data. As noted by DiMatteo, ${ }^{63}$ it is possible that a bidirectional loop exists in which depression causes noncompliance with medical treatment and noncompliance further worsen depression. Therefore, a clinical focus on both might be essential. Nevertheless, depressive symptoms may be a modifiable risk factor for poor compliance with antihypertensive medications. ${ }^{63}$

Anxiety disorders were equally quite prevalent in the study. Anxiety and hypertension share the same pathophysiological pathway which is the sympathetic pathway. ${ }^{24,25,65}$ Excessive sympathetic firing with accompanying adrenergic discharge remains the underlining pathophysiology. Suffices to say this is also the reason benzodiazepines potentiate GABA find therapeutic usefulness in both conditions. The occurrence of symptoms of hypertension alone appear to be more disabling especially as the methodology in this study excluded acute cases. Severe hypertension causes more symptoms and expectedly therefore, poses more morbidity and burden than mild to moderate hypertension. ${ }^{65}$ The physical symptoms of hypertension are largely similar to the physical symptoms of anxiety disorders, particularly, generalized anxiety disorder, and they tend to be very sensitive to adverse changes in the environment. In hypertension, little changes in the environment including change in income level, employment, marital status (prolonged difficulty, disharmony, separation, divorce or widowhood), and poor drug adherence could have profound affects on patients who had hitherto remained stable on medications. ${ }^{41,44,45}$

The prevalence of substance abuse among hypertensive patients in the study was found to be $22.7 \%$. Alcohol intake constituted the highest percentage $(n=62,17.2 \%)$. This was in agreement with the previous findings. ${ }^{16,22}$ Majority had multiple substance abuse. More than $70 \%$ of them had alcohol related disorder with greater ratio in male (5:1). Alcohol acts as a sedative agent at low doses and as a central nervous system depressant at high doses and in long term use. It acts potentiating GABA neurotransmission. ${ }^{25}$ At the long run has also been found to affect dopamine and serotonine pathways. This provides some relaxing and initialanxiolytic effects. The sedative and anxiolytic effects provide the rewards and attraction for the hypertensive patients for using alcohol to self medicate the many anxiety-like symptoms of hypertension. ${ }^{25}$ Also, the alcohol related problems together with complications of the hypertension may singly or in combination further heighten the emotional burden and this may have a negative impact on medication compliance. ${ }^{15,63}$ 
The active pharmacological ingredient in tobacco is nicotine Nicotine smoke was next most used psychoactive substance after alcohol. Few subjects used it as nicotine snuff. The aetiological link between nicotine smoke and occurrence of hypertension has long been established by several studies. ${ }^{65,67}$ Nicotine is an agonist at the nicotinic subtype of acetylcholine receptors. It activates the doparminergic pathway, causes an increase in circulating norepinephrine and epinephrine, increase in the release of vasopressin, endophine and cortisol. ${ }^{25}$ Nicotine smoke, including passive smoking has also been associated with endothelial damage. ${ }^{22,56}$ All these contribute to the stimulatory effects of the CNS, hence the tendency of causing hypertension. ${ }^{66}$ Kolanut and khat chewing, both CNS stimulants, are consumed commonly in Nigeria. They have been implicated in hypertension. ${ }^{57-59}$ Khat has been found to contain cathinone and norephedrine. ${ }^{58}$ Caffeine use primarily increases the activity of cAMP. ${ }^{27,28}$ However, it also, specifically at high dose or concentration, can enhance the activity of dopamine and noradrenergic neurones, and thereby causing an increase in blood pressure. In most cases of increased dopamine, there may be a relative decrease in acetylcholine, a neurotransmitter involved memory. Forgetful was identified as a key reason for poor adherence to ant-hypertensive medications. Cannabis and cocaine also enhance dopaminergic activity.

Curious attention to the aetiology of hypertension has prompted interesting findings. Substances of abuse particularly alcohol, nicotine, cannabis and cocaine have been implicated in the aetiology of hypertension through their respective mechanism of action. On the other hand, the frustrations particularly from functional incapacitation, need to ameriorate the disturbing symptoms, emotional disturbance especially depression and anxiety, reduced quality of life and well being all drag the individual into substance use and subsequently abuse. This simply describes the existence of a bidirectional relationship between substance abuse and hypertension..$^{27,28}$ However, stating the precise relationship was not the scope of this study. Hypertension patients tend to abuse substance mainly to self-medicate their depression or to abate the many anxiety or anxiety like symptoms that are usually present in hypertension, hence the therapeutic use of diazepam and propranolol which have proven anxiolytic effects. Conversely, consumption of caffeine ${ }^{27,28}$ and alcohol, ${ }^{47-51}$ smoking nicotine, ${ }^{22,53-56}$ cannabis and cocaine have equally been identified as strong causal factors.

\section{Conclusion}

The study reveals that essential hypertension is a chronic debilitating and disabling illness associated with common psychiatric comorbidity and substance use, with both either singly or in combination affect medication adherence. Is therefore important that the management of hypertension should include more attention to their mental health status and possible substance use among these patients in order to enhance the quality of healthcare.

\section{Limitation}

However, it was difficult for most of the respondents to know exactly the age of onset of disease since majority only became aware of the diagnosis during their first or routine hospital visits.

\section{Acknowledgements}

None.

\section{Conflict of interest}

The author declares no conflict of interest.

\section{References}

1. VicHealth. Burden of disease due to mental illness and mental healthproblems. Res Summ. 2007:1-8.

2. Whiteford HA, Ferrari AJ, Degenhardt L, et al. Global burden of disease attributable to mental and substance use disorders: findings from the global burden of disease study 2010. Lancet. 2010;382(9904):15751586 .

3. Whiteford HA, Ferrari AJ, Degenhardt L, et al. The global burden of mental, neurological and substance use disorders: an analysis from the global burden of disease study 2010. PloS One. 2015;10(2):e0116820.

4. Fields LE, Burt VL, Cutler JA, et al. The burden of adult hypertension in the United States 1999 to 2000: a rising tide. Hypertension. 2004;44(4):398-404.

5. World Health organization. A global brief on Hypertension Silent killer, global public health crisis. Switzerland, Geneva; 2013:40 p.

6. Bromfield S, Muntner P. High blood pressure: the leading global burden of disease risk factor and the need for worldwide prevention. Curr Hypertens Rep. 2013;15(3):134-136.

7. Murray CJL, Vos T, Lozano R, et al. Disability-adjusted life years (DALYs) for 291 diseases and injuries in 21 regions, 1990-2010: a systematic analysis for the global burden of disease study 2010. Lancet. 2010;380(9859):2197-2223.

8. The global economic burden of non-communicable diseases. World Econ Forum. 2016:1-48.

9. Unachukwu CN, Agomoh DI, Alasia DD. Pattern of non-communicable diseases among medical admissions in Port Harcourt, Nigeria. Niger Journal of Clin Pract. 2008;11(1):14-17.

10. Turner J, Kelly B. Emotional dimensions of chronic disease. West J Med. 2000;172(2):124-128.

11. Oshodi YO, Adeyemi JD. Oke DA, et al. Psychiatric morbidity in hypertensives attending a cardiology outpatient clinic in West Africa. Niger J Clin Pract. 2012;15(1):84-88.

12. Kumar S, Sujiv A, Selvaraj K. Pattern of mental distress among chronic disease subjects in urban Puducherry India. Chrismed J Health Res. 2015;2(2):104-108.

13. Footman K, Roberts B, Tumanov S, et al. The comorbidity of hypertension and psychological distress: a study of nine countries in the former Soviet Union. J Public Health. 2013;35(4):548-557.

14. Kretchy IA, Owusu-Daaku FT, Danquah SA. Mental health in hypertension: assessing symptoms of anxiety, depression and stress on anti-hypertensive medication adherence. Int $J$ Mental Health Syst. 2014;8:25.

15. Briganti EM, Shaw JE, Chadban SJ, et al. Untreated hypertension amongAustralian adults: the 1999-2000Australian Diabetes, Obesity and Lifestyle Study. Med J Aust 2003;179(3):135-139.

16. Bissa S, Mossie A, Gobena T. Prevalence of hypertension and its association with substance use among adults living in Jimma Town South West Ethiopia 2012. World J Med Med Sci. 2014;2(1):1-11.

17. Substance Abuse and Mental Health Services Administration, results from the 2013 National Survey on Drug Use and Health: Summary of National Findings. NSDUH Series H-48, HHS Publication No. (SMA) 14-4863. Maryland, Rockville; 2016.

Citation: Nkporbu AK, Stanley PC. Psychiatric morbidity and substance use correlated with drug compliance among subjects with essential hypertension attending the out-patient clinic of university of Port Harcourt teaching hospital (UPTH). MOJ Addict Med Ther. 20I8;5(3):I48-I56. 
18. Grant BF, Stinson FS, Dawson DA, et al. Prevalence and co-occurrence of substance use disorders and independent mood and anxiety disorders: results from the National Epidemiologic Survey on Alcohol and Related Conditions. Arch Gen Psychiatry. 2006;61(8):807-816.

19. Virdis A, Giannarelli C, Neves MF, et al. Cigarette smoking and hypertension. Curr Pharm Des. 2010;16(23):2518-2525.

20. Damena T, Mossie A, Tesfaye M. Khat Chewing and mental distress: a community based study, in Jimma City, Southwestern Ethiopia. Ethiop J Health Sci. 2011;21(1):37-45.

21. Primatesta P, Falaschetti E, Gupta S, et al. Association between smoking and blood pressure evidence from the health survey for England. Hypertension. 2001;37(2):187-193.

22. Friedman G, Klatsky AL, Siegelaub AB. Alcohol, tobacco, and hypertension. Hypertension.1982;4(5 Pt 2):143-150.

23. Dryman A, Anthony JC, DePaulo JR. Relationship between psychiatric distress and alcohol use: findings from the Eastern Baltimore Mental Health Survey. Acta Psychiatr Scand. 1989;80(4):310-314.

24. Falase AO, Akinkugbe OO. A Compendium of Clinical Medicine. Ibadan, Spectrum Books Limited; 1999;2:55-128.

25. Sadock BJ, Sadock VA. Kaplan \& Sadock's synopsis of psychiatry: behavioural sciences/clinical psychiatry. 10th edn. Philadelphia: Lippincott Williams \& Wilkins; 2007.

26. World Health Organization - International Society of Hypertension Guideline for the management of hypertension Guidelines Subcommittee. J Hypertens. 1999;17(2):151-183.

27. Jee SH, He J, Whelton PK, et al. The effect of chronic coffee drinking on blood pressure: a meta-analysis of controlled clinical trials. Hypertension. 1999;33(2):647-652.

28. Lane JD, Pieper CF, Phillips-Bute BG, et al. Caffieine affects cardiovascular and neuroendocrine activation at work and home. Psychosom Med. 2002;64(4):595-603.

29. Cutler JA, Brittain E. Calcium and blood and pressure: an epidemiologic perspective. Am J Hypertens. 1990;3(8 Pt 2):137S-146S.

30. Martins D, Pan D, Karami N, et al. The Relationship Between Body, Weight and the Prevalence of Isolated Systolic Hypertension in Older Subjects. J Clin Hypertens. 2000;2(4):248-252.

31. Murray CJ, Lopez AD. Mortality by cause for eight regions of the world Global burden of disease. Lancet. 1997;349(9061):1269-1276.

32. Cooper R, Rotimi C, Ataman S, et al. The prevalence of hypertension in seven populations of west Africanorigin. Am Public Health. 1997;87(2):160-168.

33. Rice D, Kelman S, Miller LS. The economic burden of mental illness. Hosp Community Psychiatry.1992;43(12):1227-1232.

34. Wokoma FS, Alasia DD. Blood pressure pattern in Barako: a rural community in Rivers State, Nigeria. The Nigeria Journal. 2011;11(1):1-13.

35. Akpa MR, Alasia DD, Emmen-Chioma PC. An appraisal of hospital based blood pressure control in Port Harcourt, Nigeria. The Nigeria Health Journal. 2008;8(1-2):27-30.

36. Adefuye BO, Adefuye PO, Oladepo TO, et al. Prevelence of hypertension and other cardiovascular risk factors in an African Urban, sub-urban religious community. Nigerian Medical Practitioner. 2009;55(1-2):4-8.

37. Lawoyin To, Asuzu MC, Kaufman J, et al. Prevalence of cardiovascular risk factors in an African urban inner city community. West Afr J Med. 2002;21(3):208-211
38. Pauletto P, Caroli M, Pessina AC, et al. Hypertension prevalence and agerelated changes of blood pressure in semi-nomadic and urban Oromos of Ethiopia. Eur J Epidemiol. 1994;10(2):159-164.

39. Erhun WO, Olayiwola, G, Agbani EO, et al. Prevalence of Hypertension in a University Community in South Western Nigeria. African journal of Biomedical Research. 2005;8:15-19.

40. De Ramirez SS, Enquobahrie DA, Nyadzi G, et al. Prevalence and correlates of hypertension: a cross-sectional study among rural populations in Sub-Saharan Africa. J Hum Hypertens. 2010;24(12):786-795.

41. Chhabra MK, Lal A, Sharma KK. Status of lifestyle modification in hypertension. J Indian Med Assoc. 2001;99(9):504-508.

42. Gordon HW. Hypertensive vascular disease. Harrison's principles of internal medicine. McGraw-Hill companies, Inc. edn. 2001;15(246):1414-1430.

43. Akinkugbe OO, Nivholson DM, Cruickshank JK. Health disease in blacks of Africa and the Cardiovasc. Clin. 1991;21:377-391.

44. Pickering TG. Devereux RB, James GD, et al. Environmental influences on blood pressure and the role of job strain. J Hypertens Suppl. 1996;14(5):S179-S185

45. Gwatkin DR, Guillot M, Heuveline P. The burden of disease among the global poor. Lancet. 1999;354(9178):586-589.

46. Lundsbergis PA, Hatch MC. Psychosocial work stress and pregnancyinduced hypertension. Epidemotogy. 1996;7(4):346-351.

47. Alem A, Kebede D, Kullgren G. The epidemiology of problem drinking in Butajira, Ethiopia. Acta Psychiatr Scand Suppl. 1999;397:77-83.

48. Sesso HD, Cook NR, Buring JE, et al. Alcohol consumption and the risk of hypertension in women and men. Hypertension. 2008;51(4):1080-1087.

49. Beilin LJ, Puddey IB, Burke V. Alcohol and hypertension-kill or cure? J Hum Hypertens. 1996;10(Suppl 2):S1-S5.

50. Teferra S, Medhin G, Selamu M, et al. Hazardous alcohol use and associated factors in a rural Ethiopian district: a crosssectional community survey. BMC Public Health. 2016;16:218.

51. Kebede D, Alem A. The epidemiology of alcohol dependence and problem of drinking in Addis Ababa, Ethiopia. Acta Psychiatry Scand Suppl. 1999;397:30-34.

52. Lakew Y, Haile D. Tobacco use and associated factors among adults in Ethiopia: further analysis of the 2011 Ethiopian Demographic and Health Survey. BMC Public Health. 2015;15:487.

53. Reda AA, Kotz D, Biadgilign S. Adult tobacco use practice and its correlates in eastern Ethiopia: a cross-sectional study. Harm Reduct J. 2013;10:28.

54. Thuy AB, Blizzard L, Schmidt MD, et al. The association between smoking and hypertension in a population-based sample of Vietnamese men. J Hypertens. 2010;28(2):245-250.

55. Teo KK, Ounpuu S, Hawken S, et al. Tobacco use and risk of myocardial infarction in 52 countries in the INTERHEART study: a case-control study. Lancet. 2006;368(9536):647-658.

56. Karatzi K, Papamichael C, Karatzis E, et al. Acute smoke-induced endothelial dysfunction is more prolonged in smokers than in nonsmokers. Intern J Cardio. 2007;120(3):404-406.

57. Getahun W, Gedif T, Tesfaye F. Regular Khat (Catha edulis) chewing is associated with elevated diastolic blood pressure among adults in Butajira, Ethiopia: A comparative study. BMC Public Health. 2010;10:390.

58. Toennes SW, Harder S, Scharmm M, et al. Pharmacokinetics of cathinone

Citation: Nkporbu AK, Stanley PC. Psychiatric morbidity and substance use correlated with drug compliance among subjects with essential hypertension attending the out-patient clinic of university of Port Harcourt teaching hospital (UPTH). MOJ Addict Med Ther. 20I8;5(3): I48-I56. 
and nor-ephedrine after the chewing of khat leaves. Br J Clin Pharmacol. 2003;56(1):125-130.

59. Al-Motarreb A, Briancon S, Al-Jaber N, et al. Khat chewing is a risk factor for acute myocardial infarction: a case-control study. $\mathrm{Br} \mathrm{J}$ Clin pharmacol. 2005;59(5):574-581.

60. Tesfaye F, Byass P, Wall S, et al. Association of smoking and khat (Catha edulis Forsk) use with high blood pressure among adults in Addis Ababa, Ethiopia. Prev Chronic Dis. 2008;5(3):A89.

61. Kalix P. Pharmacological properties of the stimulant khat. Pharmacol Ther. 1990;48(3):397-416.

62. Wang PS, Bohn RL, Knight E, et al. Noncompliance with antihypertensive medications: the impact of depressive symptoms and psychosocial factors. J Gen Intern Med. 2002;17(7):504-511.

63. DiMatteo MR, Lepper HS, Croghan TW. Depression is a risk factor for noncompliance with medical treatment-meta-analysis of the effects of anxiety and depression on patient adherence. Arch Intern Med. 2000;160(14):2101-2107.
64. Dhalla S, Kopec JA. The CAGE questionnaire for alcohol misuse: a review of reliability and validity studies. Clin Invest Med. 2007;30(1):3341.

65. Leone A. Biochemical markers of cardiovascular damage from tobacco smoke. Curr Pharm Des. 2005;11(17):2199-2208.

66. Lifton RP, Gharavi AG, Geller DS. Molecular mechanisms of human hypertension. Cell. 2001;104(4):545-556.

67. Glantz SA, Parmley WW. Passive smoking and heart disease. Epidemiology, physiology, and biochemistry. Circulation. 1991;83(1):1-12. 